\title{
$V$ Fórum de Desenvolvimento Regional e Meio Ambiente: a construção do trabalho acadêmico
}

O Centro Universitário de Araraquara - Uniara realizou, no dia 30 de novembro de 2012, o V Fórum de Desenvolvimento Regional e Meio Ambiente, como tema A construção do trabalho acadêmico. O evento, promovido pelo Programa de Mestrado em Desenvolvimento Regional e Meio Ambiente - Uniara, com o apoio da Capes e da Funadesp, foi voltado a pesquisadores, estudantes de graduação e pós-graduação, representantes do poder público, da sociedade civil e da iniciativa privada.

O objetivo do fórum foi dar continuidade às iniciativas do programa de divulgação dos resultados dos estudos que estão sendo desenvolvidos, bem como ampliar e fortalecer o intercâmbio com outros pesquisadores e instituições nacionais e internacionais, sempre com o objetivo de promover debates em relação às questões teóricas e metodológicas relacionadas à construção do trabalho acadêmico e divulgar pesquisas e experiências na área para a comunidade científica e sociedade.
Com mais de 100 participantes e 30 trabalhos inscritos, o evento contou com a participação de diferentes instituições públicas e particulares.

Neste ano, professores convidados avaliaram, entre os painéis apresentados, os dois que mais se destacaram. Os selecionados foram: "A Produção e Destinação de Resíduos de Óleos e Gorduras em Estabelecimentos Comerciais na Cidade de Araraquara-SP", de Silvana Aparecida de Souza, Tereza Kazuko Muroka e Maria Bernardete da Silva Malara, e "Currículo da Escola do Campo, Temática Ambiental: Análise de Documentos como Metodologia para Discussões sobre Desenvolvimento nos Assentamentos", de Claudionor Renato da Silva.

Foi a quinta edição do fórum, que vem mantendo sua periodicidade anual. Os resumos classificados estão publicados a seguir. 


\title{
SISTEMAS DE INDICADORES DE SUSTENTABILIDADE: UMAAPRECIAÇÃO A PARTIR DE CINCO CATEGORIAS DE ANÁLISE
}

\author{
BATALHÃO, André Cavalcante da Silva*; TEIXEIRA, Denilson**
}

\section{RESUMO}

Os Indicadores de Sustentabilidade são parâmetros fundamentados em fatos e experiências que refletemem um retrato atualizado os antecedentes históricos da dimensão avaliada, sendo essencial no auxílio para sinalizar o progresso em direção à sustentabilidade. As ferramentas de avaliação do desenvolvimento sustentável são utilizadas para um efeito comparativo, podendo ser adotadas em várias escalas. Uma pesquisa feita com Organizações Governamentais, ONG's, Instituições Educacionais ou de Pesquisa e Instituições Privadas demonstrou uma fragmentação entre os especialistas quanto às Metodologias de Avaliação da Sustentabilidade que consideram mais importantes. De acordo com essa pesquisa, três sistemas de indicadores somaram juntos 35,4\% das indicações, sendo: Ecological footprint method, Dashboard of sustainability e Barometer of sustainability. Nota-se que essas metodologias se diferenciam a partir de tais categorias de análise: quanto ao seu escopo, esfera, dados, participação e interface. O objetivo da pesquisa aqui realizada foi evidenciar as diferenças entre as ferramentas de avaliação da sustentabilidade utilizando as cinco categorias de análise citadas na pesquisa referenciada, partindo da premissa que essas ferramentas procuram mensurar a sustentabilidade e que tem aceitação no contexto internacional por especialistas da área. Através de pesquisa bibliográfica, consulta a órgãos internacionais ligados a temática ambiental e um levantamento das ferramentas de avaliaçãocitadas na literatura, partiu-se a proposta de salientar e demonstrar as principais características das ferramentas consideradas mais aceitas. Os Sistemas de Indicadores são mecanismos de articulação para manutenção e geração de políticas públicas ambientais, compondo o processo de desenvolvimento.

Palavras-chave: Ferramentas de Avaliação; Desenvolvimento Sustentável; Indicadores de Sustentabilidade.

*Programa de Mestrado em Desenvolvimento Regional e Meio Ambiente da Uniara, Araraquara/SP.

**Universidade Federal de Goiás - UFG, Goiânia/GO e Programa de Mestrado em Desenvolvimento Regional e Meio Ambiente da Uniara, Araraquara/SP. 


\section{CURRÍCULO DA ESCOLA DO CAMPO, TEMÁTICAAMBIENTAL: ANÁLISE DE DOCUMENTOS COMO METODOLOGIA PARA DISCUSSÕES SOBRE DESENVOLVIMENTO NOS ASSENTAMENTOS}

SILVA, Claudionor Renato da*

\section{RESUMO}

O currículo da escola do campo vem sendo discutido pelas políticas públicas educacionais federais, articulando a unidade escolar e seu entorno. No caso da educação do campo nos assentamentos rurais, essa articulação se amplia para dimensões socioeconômicas, ambientais e de desenvolvimento. A ideia-chave que perpassa esses documentos é o da formação educacional ambiental sustentável. Partindo dela, é evidenciado que o currículo escolar, anunciado no Projeto Político Pedagógico dessas escolas, deve cumprir a proposta de formação em que estejam presentes temas relacionados ao meio ambiente, à sustentabilidade e ao desenvolvimento dos assentamentos. O presente trabalho objetiva refletir sobre como a metodologia da Análise de Documentos pode trazer contribuições à discussão do desenvolvimento dos assentamentos, nas aulas dos anos iniciais, numa perspectiva interdisciplinar, em que o educando constrói sua identidade e formação cidadã crítica rural/urbana. Sobre a Análise de Documentos, esta se dá em cinco etapas: $1 .^{a}$ ) o contexto da produção; $2 .^{a}$ ) autor/autores; 3. ${ }^{a}$ ) autenticidade e confiabilidade; $4 .^{a}$ ) natureza do texto; $5 .^{a}$ ) conceitos chave e lógica interna. Seguindo essas etapas da metodologia, no Projeto Político Pedagógico de uma escola do campo do interior paulista, foi possível destacar assuntos relacionados ao desenvolvimento dos assentamentos ligados (1) à educação escolar contextualizada ao assentamento rural, como política pública; (2) à atualidade das pesquisas e produções da sociologia rural quanto às novas ruralidades e a reforma agrária; (3) ao meio ambiente e à sustentabilidade, considerando questões voltadas à patrimonialidade ambiental, preservação ambiental e palavras-chave relacionadas ao desenvolvimento socioambiental.

Palavras-chave: Projeto Político Pedagógico; Escola do campo; Assentamentos; Ambiental; Desenvolvimento.

*Universidade Estadual Paulista Júlio de Mesquita Filho, Campus Araraquara. UNESP/FCLAr. 


\title{
OS CONTEÚDOS DE EDUCAÇÃO AMBIENTAL DOS MATERIAIS DO SISTEMA DO SERVIÇO SOCIAL DA INDÚSTRIA - SESI: $6^{\circ}$ AO $9^{\circ}$ ANOS DO ENSINO FUNDAMENTAL
}

\author{
PEREIRA, Edna Lins dos Santos*; ARAÚJO, Danielle dos Santos*; RIBEIRO, Maria Lúcia*
}

\section{RESUMO}

O currículo das escolas do ensino fundamental do município de Araraquara, a partir do ano de 2011, adotou os materiais do Sistema SESI. Nesse sistema, o processo de ensino e de aprendizagem está centrado na construção do conhecimento, tendo no aspecto interdisciplinar e na organização dialógica as suas principais bases. A interdisciplinaridade é o eixo básico da proposta pedagógica do SESI, que pressupõe diálogo não apenas entre os diferentes campos do conhecimento, mas também entre o professor e o aluno. Este estudo foi realizado por meio de análise documental dos materiais didáticos do Sistema SESI: livros dos alunos e dos professores, de todas as disciplinas elencadas na grade curricular selecionando os conteúdos que abordam, direta ou indiretamente, a temática ambiental. Foram obtidas informações sobre as oito disciplinas que compõem o currículo do $6^{\circ}$ ao $9^{\circ}$ anos do ensino fundamental. Os conteúdos ambientais são apresentados nas disciplinas de língua portuguesa, matemática, história, geografia, ciências e arte de modo fragmentado sem uma sequência lógica entre as disciplinas, ou seja, não segue o conceito de Educação Ambiental como um tema transversal. As disciplinas de inglês e educação física não trabalham nenhum tópico ambiental. Esses recortes sugeremque nem mesmo os três compartimentos ambientais (água, ar e solo) são ensinados nos anos selecionados do ensino fundamental nesta investigação. Devem ser destacados alguns problemas em relação ao uso desses materiais: exigência da internet para realizar atividades propostas, por exemplo. É importante ressaltar que aSecretaria de Educação Municipal, juntamente com o SESI, têm realizado alguns cursos de capacitação para prepararos professores para trabalhar o material comos alunos.

Palavras-chave: Ensino Fundamental, Educação Ambiental, Sistema SESI.

*Programa de Mestrado em Desenvolvimento Regional e Meio Ambiente da Uniara, Araraquara/SP. 


\section{POLÍTICANACIONAL DE EDUCAÇÃO AMBIENTAL: COMO SEAPLICA?}

YAVORSKI, Rosely*; PRINTES, Liane Biehl*

\section{RESUMO}

De acordo com a Política Nacional de Educação Ambiental, Lei n. 9795/99: "A Educação Ambiental é um componente essencial e permanente na educação nacional, devendo estar presente, de forma articulada, em todos os níveis e modalidades do processo educativo, em caráter formal e não-formal." Trata-se de umartigo da lei importante por trazer direcionamento para a Educação Ambiental em todos os níveis de educação. Podemos dizer que Educação Ambiental é um exercício para a cidadania, os professores devem estar preparados para exercer e conduzir seus alunos para esse exercício. Diante de tal afirmação, esta pesquisa tempor objetivo verificar de que forma a educação ambiental é abordada no processo de formação aos professores. Para atingilo, foi realizada uma análise das grades curriculares e das ementas das disciplinas de duas instituições superiores, uma instituição estadual do Paraná, e outra particular de São Paulo. Diferenciamos as instituições eEstados por ser a lei de nível federal; assim, entendemos que as instituições reconhecem essa necessidade. Após análise realizada, não encontramos menção à Educação Ambiental em nenhuma das grades curriculares e ementas analisadas, mas as ementas do curso de pedagogia versa que os profissionais devem estar preparados para fazer uma leitura crítica da realidade, usando a interdisciplinaridade em suas análises. Concluímosque: apesar de estar na lei e as ementas dos cursos falarem sobre a análise crítica da realidade de uma maneirainterdisciplinar, não podemos afirmar que isso realmente aconteça; para tanto, precisamos aprofundar mais nossos conhecimentos através de entrevista e participação em aulas desses professores.

Palavras-chave: Educação Ambiental; Processo educativo; Profissionais de pedagogia; Lei n. ${ }^{\circ}$ 9795/99.

*Centro Universitário de Araraquara - Uniara, Araraquara/SP. 


\title{
A EFETIVIDADE DA EDUCAÇÃO AMBIENTAL REALIZADA NO PARQUE DO BASALTO - ARARAQUARA/SP POR ESTUDANTES DE BIOLOGA E TURISMO DA UNIARA
}

\author{
LEMES, MarciAparecida*; BORINO, Salete*; VIANNA; Paulo Sérgio Aparecido*; \\ MAIA, Mara Cristina*; OLIVEIRA, Haydée Torres**
}

\begin{abstract}
RESUMO
O comportamento do ser humano em relação ao meio ambiente é preocupante. A Educação Ambiental é peça-chave para uma convivência mais respeitosa entre seres humanos e natureza. Imbuídos dessa preocupação, alunos do curso de Biologia e Turismo da Uniara promovem atividades de monitoria visando sensibilizar estudantes da rede pública municipal, visitantes do Parque do Basalto, problematizando a relação ser humano-meio ambiente, e despertando neles a percepção dessa interdependência e a necessidade de rever posturas, valores e atitudes no sentido de construirmos uma sociedade que se preocupe com a dimensão socioambiental. $\mathrm{O}$ grupo de estudo responsável por esse artigo acompanhou uma visita monitorada e efetuou a coleta de dados, procurando observar as atividades desenvolvidas pelos monitores no Parque do Basalto (Araraquara/SP) por meio de visitas e dinâmicas, assumindo os pressupostos da EA Crítica para indicar quais os princípios de consolidação da cidadania eram trabalhados. A análise dos dados coletados, aliada ao fato de que a construção de propostas educativas, nas suas dimensões tanto políticas quanto pedagógicas, deve ter como horizonte a transformação dos indivíduos na direção de posturas críticas e pró-ativas em relação ao ambiente, apontou para a continuidade do programa da forma implantada. Concluiu-se que os objetivos do ecoturismo no parque não se limitavam ao pensamento conservacionista da preservação, mas iam além do que prevê a LPALei n. ${ }^{\circ}$ 9.795/99, atendendo ao que sugerem os PCNs, que atribuem à EA aplicada caráter transversal e interdisciplinar. Concluiu-se ainda que somente uma educação ambiental crítica fará com que a crise ambiental atual seja enfrentada de forma adequada, levando a resultados efetivos de sustentabilidade e preservação do ambiente.
\end{abstract}

Palavras-chave: Educação Ambiental; Parque do Basalto; Visitas monitoradas; Sustentabilidade.

*Centro Universitário de Araraquara - Uniara, Araraquara/SP.

**Universidade Federal de São Carlos - UFSCar/SP. 


\title{
IMPLANTAÇÃO DO PROJETO FARMÁCIA VIVA NO PARQUE ECOLÓGICO DO BASALTO EM ARARAQUARA/SPE EDUCAÇÃO AMBIENTAL
}

\author{
KOSHIMA, Fernanda*
}

\section{Resumo}

O ritmo de vida acelerado da população e outros fatores contribuíram para que houvesse uma queda emsua qualidade de vida. Devido a esse fato, a busca pela melhoria na qualidade de vida tem contribuído para que estudos, pesquisas e projetos sobre plantas medicinais fossem estimulados para que toda a população possa ter acesso a essas hortaliças sem altos custos. De acordo com o Ministério da Saúde, em 2006, aproximadamente $70 \%$ dos medicamentos são feitos a partir das plantas. Dessa forma, o governo federal tem incentivado as Unidades Básicas de Saúde - UBS a adotarem terapias com o uso de plantas medicinais e a fitoterapia através da Farmácia Viva. Esse projeto visa à utilização de plantas e hortaliças medicinais na alimentação da população, procurando melhorar sua qualidade de vida, além da acessibilidade desses recursos benéficos à saúde. $\mathrm{O}$ projeto Farmácia Viva será implantado no Parque Ecológico do Basalto, localizado no município de Araraquara/ SP. Essas plantas poderão ser consumidas pelos visitantes do parque, promovendo o resgate e a valorização da cultura popular através de práticas e técnicas de cultivo de hortaliças e plantas medicinais, além dos cuidados que se deve ter com relação à preservação da natureza e de seus recursos. Pretende-se cultivar 20 espécies, com as quais os visitantes terão um contato mais próximo e aprenderão sobre seus benefícios, como plantá-las e utilizá-las em suas residências através de receitas alimentares. Além disso, o projeto possibilitaque os visitantes possam transmitir ensinamentos e incentivos aos filhos e vizinhos, incentivando o consumo de hortaliças e a importância da preservação do meio ambiente e o respeito que se deve ter com a natureza.

PalaVras-chave: Plantas medicinais; Alimentação; Educação Ambiental.

*Centro Universitário de Araraquara - Uniara, Araraquara/SP. 


\section{REVISÃO BIBLIOGRÁFICA: DISPERSÃO DE SEMENTES EM ÁREAS DE CERRADO DO ESTADO DE SÃO PAULO, COM ÊNFASE EM ORNITOCORIA}

DONADON, Juliana Trevisoli*

\section{RESUMO}

A fauna e a flora dos ecossistemas do Cerrado estão sendo comprometidas pela exploração, podendo ocorrer extinção biológica e ecológica de espécies vegetais que dependem de animais para a dispersão e controle de suas populações. Este trabalho tem como objetivo realizar levantamento bibliográfico sobre estudos referentes à dispersão de sementes nas áreas de Cerrado do Estado de São Paulo; discutir a importância dos mecanismos dispersores para a manutenção de tais áreas, focalizando a ornitocoria. A revisão está sendo realizada em periódicos nacionais de Ecologia, Botânica e Ornitocoria publicados nos últimos 12 anos, utilizando as palavras-chave: dispersão, sementes, ornitocoria, Estado de São Paulo. Resultados preliminares indicam a espécie Dacnis cayana como potencial dispersor de quatro espécies de plantas: Davilla rugosa (Dilleniaceae) em São Carlos; Alchornea glandulosa (Euphorbiaceae) em São Manuel; Talauma ovata (Magnoliaceae) em Rio Claro, Araras e São Carlos; Rapanea ferruginea (Myrsinaceae) em São Manuel. A espécie Empidonomus varius se apresentou como dispersora das mesmas espécies de plantas que $D$. cayana, com o acréscimo de Ocotea pulchela (Lauraceae) em São Carlos. A espécie Mimus saturninus apareceu como potencial dispersora das mesmas espécies de plantas que Empidonomus varius, excluindo D. rugosa. A espécie Myiodynastes maculatus parece ser potencial dispersora das mesmas espécies de plantas que $D$. cayana, excluindo A. glandulosa e acrescentando Miconia rubiginosa (Melastomataceae) em Itirapina. Os pássaros D. cayana, E. varius, M. saturninus e M. maculatus são importantes dispersores de sementes nos fragmentos de Cerrado do Estado de São Paulo, podendo contribuir para a regeneração natural e recuperação dessas áreas.

Palavras-chave: Dispersão; Sementes; Cerrado; São Paulo.

*Centro Universitário de Araraquara - Uniara, Araraquara/SP. 


\title{
ANÁLISE DE TESES E DISSERTAÇÕES COM O TEMAARBORIZAÇÃO URBANA E ARBORIZAÇÃO VIÁRIA NO PERÍODO DE 2006 A 2010
}

\author{
LEMES, Marci Aparecida*; GONÇALVES, Thiago Oliveira*; \\ BORINO Salete*; TEIXEIRA, Denilson **
}

\begin{abstract}
RESUMO
O saber se renova por meio das publicações dos trabalhos científicos. O estudo analisou 38 trabalhos compostos de teses e dissertações, selecionados pelas palavras-chave arborização viária e arborização urbana, no período dos anos de 2006 a 2010, disponíveis no banco de dados da CAPES. Os dados coletados em revisão da literatura foram organizados em uma base e analisados pelo método quantitativo. O objetivo da pesquisa foi verificar o grau de interesse dos programas e das instituições em um panorama regionale federal. Os resultados obtidos foram combinados de formas independentes entre si, o que propiciou múltiplos corolários: dos 38 trabalhos, 33 são dissertações e 5 são teses; a palavra-chave mais utilizada foi arborização urbana, com $76,32 \%$, e a menos foi arborização viária, com 10,53\%; a instituição que mais produziu sobre o tema foi a ESALQ/USP, totalizando 7; o programa de geografia foi o que mais estudou o assunto, com 18,42\%; a área de concentração que mais se dedicou foi a de Arquitetura e Urbanismo, com 13,16 \%; o Estado da Federação que mais se destacou foi o Estado de São Paulo, com 36,84\%; a região mais produtiva foi a Sudeste e a que não efetuou nenhuma foi a Norte; o ano em que mais ocorreram defesas foi o de 2009, com 31,58\%. Conclui-se, pela utilização no período das palavras-chave, que o tema arborização viária é muito pouco estudado, merecendo maior dedicação por ser de fundamental importância para a melhora da biodiversidade e da qualidade de vida do ser humano.
\end{abstract}

Palavras-chave: Arborização urbana; Arborização viária; Anos de 2006 a 2010; Panorama nacional.

*Centro Universitário de Araraquara - Uniara, Araraquara/SP.

**Universidade Federal de Goiás/GO. 


\section{INSETOS AQUÁTICOS COMO FERRAMENTA PARAAVALIAÇÃO DO SEDIMENTO DE CÓRREGOS LOCALIZADOS EM ÁREAS SOB DIFERENTES SITUAÇÕES AMBIENTAIS}

HIGASHI, Erika Silva*

\section{Resumo}

O processo de expansão agrícola do Brasil caracterizou-se pela falta de planejamento e consequente destruição dos recursos naturais e devastação florestal. Isso resultou em um conjunto de problemas ambientais, como a extinção de várias espécies da fauna e da flora, as mudanças climáticas locais, a erosão dos solos eo assoreamento dos cursos d'água pela retirada das matas ciliares. Estudos têm demonstrado que, principalmente em áreas sem vegetação de proteção (mata ciliar), as substâncias químicas (metais pesados, fertilizantes, herbicidas e pesticidas) utilizadas no plantio de diferentes culturas são carreadas para os corpos d'água através do processode lixiviação do solo, podendo contaminar a água e o sedimento desses ambientes e acarretar problemas de bioacumulação em grupos de diferentes níveis tróficos. O presente estudo tem como objetivo analisar detalhadamente em laboratório os efeitos do sedimento, coletado em córregos, sobre a biologia de diferentes espécies de insetos aquáticos Chironomus xanthus e Goeldichironomus luridus, criados em laboratório, e contribuir com um maior conhecimento sobre os impactos de metais provenientes da atividade agrícola para a biota aquática.

Palavras-Chave: Córregos; Insetos Aquáticos; Metais; Sedimentos.

*Centro Universitário de Araraquara - Uniara, Araraquara/SP. 


\title{
ENTOMOFAUNAASSOCIADAA MACRÓFITAS AQUÁTICAS EM LAGOAS ADJACENTES À REPRESA DO RIBEIRÃO DAS ANHUMAS (AMÉRICO BRASILIENSE/SP)
}

\author{
MELO, Elen Vicente*; AMARAL, Gabrielle Fioranelli do*; FALAVINIA, Gabriel Munhoz*; \\ ALCORINTE, Marina*; REIS, Mirela Zavitoski dos*; GORNI, Guilherme Rossi*
}

\section{Resumo}

Pesquisas sobre insetos aquáticos vêm sendo muito difundidas nos últimos anos. Entretanto, existem lacunas sobre o conhecimento de suas relações com macrófitas aquáticas. O objetivo deste trabalho foi analisar a composição e estrutura da entomofauna associadas à macrófitas aquáticas em lagoas adjacentes à represa do Ribeirão das Anhumas, localizada na Região Central do Estado de São Paulo. A coleta foi realizada emagosto de 2012, sendo selecionados quatro gêneros de macrófitas: Egeria, Utricularia, Eleocharis e Salvinia. Visando tornar a análise das estimativas numéricas mais uniformes, as amostras vegetais foram tomadas em 100 gramas de biomassa (peso úmido) de cada gênero. A remoção das macrófitas do ambiente foi feita como auxílio de uma peneira com malha $0,21 \mathrm{~mm}$ e, após a pesagem, as plantas foram acondicionadas em galões plásticos contendo água do próprio ambiente. No laboratório, as amostras foram triadas e os organismos encontrados, fixados em formol $10 \%$ e, posteriormente, conservados em álcool $70 \%$. Após procedimentos de identificação, foram registrados 268 organismos, distribuídos por 5 ordens ( 8 famílias). Dentre os táxons observados, Diptera apresenta-se como a ordem mais abundante (93\%), seguida de Ephemeroptera, representando aproximadamente $3 \%$ do total de organismos.

PalaVRas-ChaVe: Insetos; Plantas aquáticas; Fauna associada; Lagoas marginais.

*Centro Universitário de Araraquara - Uniara, Araraquara/SP. 


\title{
OLIGOCHAETA (ANNELIDA: CLITELLATA) ASSOCIADO A MACRÓFITAS AQUÁTICAS EM LAGOAS ADJACENTES À REPRESA DO RIBEIRÃO DAS ANHUMAS
}

\author{
SANCHES, Nathalie Aparecida de Oliveira*; GORNI, Guilherme Rossi*
}

\section{Resumo}

Os oligoquetos são importantes constituintes da fauna bentônica e um dos grupos mais atuantes no fluxo de energia e reciclagem de matéria orgânica nos ecossistemas lacustres. Além disso, é preciso reconhecer a importância desse táxon para a avaliação da qualidade de ecossistemas aquáticos, evidenciando sua contribuição em processos de biomonitoramento e biorrevolvimento. Assim, o presente trabalho tem como objetivo inventariar as espécies de oligoquetos associados a macrófitas aquáticas em lagoas adjacentes à represa do Ribeirão das Anhumas, localizada na Região Central do Estado de São Paulo, motivado pela escassez de informações sobre a estrutura da comunidade e suas relações com os ambientes lênticos no Brasil. As coletas das macrófitas foram iniciadas em Agosto de 2012, estendendo-se até Maio de 2013, em intervalos trimestrais. As plantas coletadas, pertencentes aos gêneros: Egeria, Utricularia, Eleocharis e Salvinia, foram lavadas sobre uma peneira granulométrica com malha de $0,21 \mathrm{~mm}$, visando ao desprendimento e à seleção dos macroinvertebrados. Os oligoquetos separados foram fixados em formolina $10 \%$ e identificados até o nível de espécie. Na primeira coleta, realizada em Agosto de 2012, foram registrados 131 oligoquetos, distribuídos em duas famílias: Família Naididae (Subfamília Naidinae e Subfamília Tubificinae) e Família Opistocystidae. Os gêneros mais abundantes foram Stylaria, representando 31,3\% da amostra, seguido pelo gênero Dero, com 28, $2 \%$.

PalaVra-chave: Fauna associada; Lagoas marginais; Microdrilli; Plantas aquáticas.

*Centro Universitário de Araraquara - Uniara, Araraquara/SP. 


\section{AGRICULTURA ORGÂNICA NA REGIÃO CENTRAL DO ESTADO DE SÃO PAULO: CARACTERÍSTICAS BÁSICAS DOS PRODUTORES E DA PRODUÇÃO}

NOGUEIRA, Naiara Souza*

\section{Resumo}

A agricultura orgânica tem como princípios básicos a utilização de processos mais limpos de produção, que evitam a contaminação e degradação ambientais, através da preservação da fertilidade natural do solo, da não utilização de adubos químicos, entre outros fatores. No Brasil, a produção e demanda de produtos orgânicos é ainda pouco expressiva, mas tem-se expandido consideravelmente nos últimos anos. Na região central do Estado de São Paulo há um relevante número de produtores que praticam esse tipo de manejo. Sendo assim, verificou-se a necessidade de caracterizar as unidades de produção agrícola orgânicas da região, bemcomo as características básicas dos produtores envolvidos. Como metodologia, optou-se por um estudo de caso, onde foi empregada a pesquisa de campo exploratória, através da realização de entrevistas semiestruturadas com os produtores orgânicos (tanto aqueles que já obtiveram a certificação de seus produtos ou que ainda estão em fase de conversão para a agricultura orgânica). Na região de estudo foram identificados 22 produtores e 2 cooperativas. Foram entrevistados, até o momento, 5 produtores ( 3 pertencentes à mesma cooperativa, estando 1 deles ainda em processo de conversão, e 2 não cooperativados). Como características dos produtores, temse que $80 \%$ dos entrevistados estão na faixa etária de 48 a 58 anos de idade, têm ensino superior completo, trabalham com agricultura orgânica há 7 anos ou menos, e sempre estiveram na região onde atualmentepossuem a produção. Como características da produção, verificou-se que $80 \%$ são pequenas unidades de produção, e que $100 \%$ dos produtores possuem como mecanismo de avaliação da conformidade a certificação por auditoria de terceira parte. Além disso, todos relataram que adotaram o sistema por filosofia de vida. As dificuldades apresentadas também são semelhantes, sendo as principais: a falta de assistência técnica e de sementes orgânicas; a fraca interface entre universidades e geração de conhecimento para a agricultura orgânica; e o custo da análise da água.

Palavras-chave: Agricultura orgânica; Características dos produtores e da produção; Região central do Estado de São Paulo.

*Universidade Estadual de Campinas - Unicamp, Limeira/SP. 


\section{CUSTO DE PRODUÇÃO DE PODISUS NIGRISPINUS COMO AGENTE DE CONTROLE BIOLÓGICO CRIADO COM PLUTELLA XYLOSTELLA}

VIEIRA, Natalia Fernanda*; DE BORTOLI, Sergio Antonio**

\section{Resumo}

Os entomologistas envolvidos com controle biológico enfrentam desafios em relação à comercialização e o aumento do uso de inimigos naturais no Manejo Integrado de Pragas - MIP. Portanto, uma das respostas a esse desafio é a redução do custo de criação dos agentes, por meio do aperfeiçoamento nas técnicas de criação e do aumento da eficácia dos agentes de controle biológico no campo. Dentre os agentes de controle biológico destacam-se particularmente os do gênero Podisus, importante no combate a insetos inimigos de plantas. Podisus nigrispinus é um percevejo predador encontrado em abundância na região neotropical. Lagartas de Plutella xylostella são presas adequadas para P. nigrispinus e sua criação é facilmente conduzida em laboratório. Para avaliar as características biológicas do predador $P$. nigrispinus foram utilizadas como presas lagartas de quarto estádio de $P$. xylostella. Neste estudo foi considerado somente o custo operacional total (custo operacional efetivo + depreciação do custo dos itens específicos), sendo assumido que o produtor já possui uma biofábrica onde os inimigos naturais podem ser criados. O objetivo do presente trabalho foi determinar o custode produção do predador P. nigrispinus criado com lagartas de P. xylostella. Para a presa $P$. xylostella, o custo de produção de cada lagarta criada em folhas de couve foi de $\mathrm{R} \$ 0,005$, e cada folha utilizada para criação das presas custa $\mathrm{R} \$ 0,019$. O custo de produção estimado para o predador $P$. nigrispinus criado em laboratório foi de $\mathrm{R} \$ 0,003$.

Palavras-chave: Custo de produção; Podisus nigrispinus; Plutella xylostella; Controle biológico.

*Centro Universitário de Araraquara - Uniara, Araraquara/SP.

**Professor-titular da Universidade Estadual Paulista Júlio de Mesquita Filho - Unesp, Jaboticabal/SP. 


\title{
O IMIGRANTE JAPONÊS NO CULTIVO DA TERRA E O USO DE AGROTÓXICOS EM TAQUARITINGA/SP: UM OLHAR NO PASSADO
}

\author{
KIKUTHI, Olimpio Massaaki*; RIBEIRO, Maria Lúcia**
}

\section{Resumo}

A participação dos imigrantes japoneses na agricultura brasileira teve um papel importante no desenvolvimento do país e, junto com outras nacionalidades, ajudaram a construir um modelo reconhecido no mundo todo pelos padrões de qualidade e produtividade. A busca por uma agricultura sustentável, que cause o menor impacto ambiental possível, tem sido objeto de muitos estudos e discussões pela academia, teóricos, especialistas e pesquisadores, em todos os níveis. Investigar um período que representa uma fase importante para a agricultura nacional implica buscar informações sobre como os imigrantes faziam o cultivo da terra, quais as técnicas empregadas e como procediam no uso de agrotóxicos. O trabalho em desenvolvimento tem como objetivo uma investigação sobre as famílias japonesas que chegaram ao Brasil no período de 1908 e 1924, considerado por alguns pesquisadores como "fase experimental", e entre 1925 e 1941, que ficou conhecida como a fase da "imigração em massa". A pesquisa será conduzida com os remanescentes das famílias japonesas que se estabeleceram em Taquaritinga/SP, e os dados serão coletados por meio de entrevistas centradas nos seguintes aspectos: resgate das histórias de vida, o trabalho na agricultura, as dificuldades encontradas pelas diferenças culturais e a discriminação racial sofrida. Entender como se estabelece o apego à terra e a valorização dos recursos naturais pode ser um caminho para equacionar as questões ambientais. Recuperar informações de um momento histórico é uma maneira de compreender ou trazer à tona novas discussões sobre mitos e rótulos impostos aos japoneses no Brasil.

Palavras-chave: Imigração japonesa; Cultivo da terra; Uso de agrotóxicos.

\footnotetext{
*Programa de Mestrado em Desenvolvimento Regional e Meio Ambiente do Centro Universitário de Araraquara - Uniara. **Doutora em Química pelo Instituto de Química da Universidade Estadual Paulista - UNESP/Araraquara e docente e pesquisadora do Programa de Mestrado em Desenvolvimento Regional e Meio Ambiente do Centro Universitário de Araraquara - Uniara.
} 


\title{
ANÁLISE DA ROTULAGEM DE PRODUTOS À BASE DE SOJA NO MUNICÍPIO DE ARARAQUARA
}

\author{
TRALDI, Daiane Roncato Cardozo*; MARTINEZ, Julian*; ROSSI, Elizeu Antonio*
}

\section{RESUMO}

Este trabalho apresenta como objetivo principal analisar a rotulagem de alimentos, especificamente de produtos derivados da soja, em relação às exigências das legislações brasileiras, no município de Araraquara/SP. Primeiramente, foi realizada uma pesquisa bibliográfica, por meio de artigos e documentos sobre as legislações brasileiras (resoluções, portarias e instruções normativas) relacionadas à rotulagem de alimentos comercializados no país, localizadas em bases virtuais, como a Scientific Eletronic Library Online - SciELO e o Ministério da Saúde. A coleta de dados ocorreu no mês de outubro de 2012, por meio do levantamento (aquisição) de 81 produtos à base de soja (sendo encontrados 31 tipos de alimentos e 45 marcas diferentes), ofertados em dois estabelecimentos de comercialização de alimentos e bebidas, localizados na região central de Araraquara (Extra Supermercados e Kari-Kari). Para a análise dos dados, será utilizado como parâmetros indicadores relacionados às exigências encontradas nas diversas legislações brasileiras para alimentos embalados e rotulagemnutricional, como, por exemplo: idioma, identificação de origem, prazo de validade, ingredientes, conteúdos líquidos, nutrientes, alimentos diet e transgênicos, frases complementares, entre outros mais específicos. Como possíveis resultados, espera-se detectar a porcentagem de irregularidades e conformidades existentes na rotulagem desses produtos, uma vez que a maioria dos estudos aponta para um grande índice de irregularidades.

PalaVras-chave: Alimentos à base de soja; Rotulagem nutricional; Legislação brasileira.

**FCF-UNESP/Araraquara. 


\title{
A PRODUÇÃO E DESTINAÇÃO DE RESÍDUOS DE ÓLEOS E GORDURAS EM ESTABELECIMENTOS COMERCIAIS NA CIDADE DE ARARAQUARA/SP
}

\author{
SOUZA, Silvana Aparecida de*; MURAOKA, Teresa Kazuko*; MALARA, Maria Bernadete da Silva*
}

\section{RESUMO}

Nos dias atuais, a geração de resíduos pode ser apontada como um fator que compromete diretamente a qualidade ambiental. Dentre os produtos consumidos e descartados, muitas vezes em grandes volumes esem uma destinação correta, estão os óleos e as gorduras. Surge então como necessidade a realização de pesquisas nesse contexto. Em Araraquara, a Cooperativa Acácia realiza a coleta seletiva, inclusive do óleo usado, mas não dispõe de dados relativos a esses resíduos. Para tanto, o presente trabalho averiguou os locais com alto potencial de geração desses resíduos, volume descartado e a destinação dos mesmos. Foi escolhida uma área amostral na cidade de Araraquara, onde há grande concentração de estabelecimentos comerciais que manipulam alimentos fritos e cem entrevistas realizadas. Do total de estabelecimentos estudados, os maiores percentuais corresponderam às categorias: restaurante e lanchonete/pastelaria, respectivamente 36 e $35 \%$, e os menores percentuais, 18 e 11\%, às categorias: bar e manipuladora de alimento. Com relação à destinação do óleo usado, há uma tendência das categorias: restaurante, lanchonete/pastelaria e bar, de separar e vender seus resíduos e manipuladora de alimento/outros, de separar e doar. Há ainda comerciantes que trocam seus resíduos e outros declararam estar armazenando os mesmos para posteriormente serem doados. Aos entrevistados, foi sugerida a doação do óleo para a Cooperativa Acácia e ofertada uma bombona para armazenar esse resíduo. Com isso, $18 \%$ deles aceitaram doar seu óleo usado, ao passo que 4\% já doavam para a cooperativa e $78 \%$ não aceitaram doar, pois já comercializavam seus resíduos. Constatou-se na cidade de Araraquara que praticamente todos entrevistados destinam corretamente o óleo usado e o usam como um meio de troca.

Palavras-chave: Coleta seletiva; Óleo de cozinha usado; Estabelecimentos comerciais.

*Centro Universitário de Araraquara - Uniara, Araraquara/SP. 


\section{DESCARTE DE MEDICAMENTOS DE CONTROLE ESPECIAL: UMA INVESTIGAÇÃO EM FARMÁCIAS E DROGARIAS EM SÃO CARLOS/SP}

DE PIETRO, Edson Cleber*

\section{Resumo}

Dentro dos Resíduos de Serviço de Saúde - RSS, encontramos os Medicamentos de Controle Especial MCE, que só podem ser dispensados com a retenção da receita, pois, quando descartados de maneira incorreta, podem causar diversos danos aos seres vivos, devido à presença de agentes neurotóxicos, teratogênicos, carcinogênicos e mutagênicos. Nesse contexto, este trabalho tem como objetivo avaliar a destinação final dos Medicamentos de Controle Especial - MCE vencidos e avariados das farmácias e drogarias do município de São Carlos/SP. Para desenvolver este projeto podemos avaliar como empresas especialistas em descartefazem o manejo desses resíduos, verificar junto à Vigilância Sanitária Municipal as farmácias e drogariasque contratam essas empresas e de que forma as que não contratam tratam esses resíduos e, com esses dados, fazer uma comparação entre os procedimentos adotados e as normas vigentes.

Palavras-chave: Resíduos de Serviço de Saúde; Medicamentos de Controle Especial; Descarte.

*Programa de Mestrado em Desenvolvimento Regional e Meio Ambiente da Uniara, Araraquara/SP. 


\title{
APLICABILIDADE DO INVENTÁRIO DE DEPRESSÃO DE BECK (BDI-II) EM IDOSOS
}

\author{
GIL, Eliana Molina*; EBISUI, Cássia Tiême Nagasawa**
}

\section{Resumo}

Todo organismo multicelular possui um tempo limitado de vida e sofre mudanças fisiológicas como passar do tempo. A vida de um organismo multicelular costuma ser dividida em três fases: a fase de crescimento, a fase de reprodução e a senescência, ou envelhecimento. $O$ termo depressão pode significar um sintoma que faz parte de inúmeros distúrbios emocionais, sem ser exclusivo de nenhum deles; como também uma síndrome traduzida por muitos e variáveis sintomas somáticos; ou ainda uma doença caracterizada por marcantesalterações afetivas. Em episódios típicos, de todas as três variedades - leve (F32.1), moderado (F32.2) e grave (F32.2 e F32.3) -, o indivíduo usualmente sofre de humor depressivo, perda de interesse e prazer e energia reduzida, levando a uma fragilidade aumentada e atividade diminuída. Considera-se que "o tipo de neurose maisencontrada é a depressão, inclusive se denomina "o resfriado comum da enfermidade mental". Diante desse contexto, a investigação de depressão em idosos torna-se cada vez mais relevante, visto que é uma enfermidade de saúde mental muito prevalente e que, frequentemente, é considerada uma decorrência natural do processo de envelhecimento. O objetivo foi detectar a prevalência da sintomatologia depressiva através da aplicação do teste Inventário de Depressão de Beck - BDI-II em idosos que residem na Obra Unida São Vicente de PaulaVila Vicentina em um município do Estado de São Paulo. Os resultados foram analisados através da técnica quantitativa, análise descritiva e crítica reflexiva com diálogo com autores renomados no tema e, por fim, a conclusão de acordo com os dados colhidos durante a pesquisa. Participaram do estudo 23 idosos, contabilizando 1 desistência. Desses entrevistados, 11 são mulheres, o que corresponde a (48\%), e 12 homens (52\%). É importante ressaltar a faixa etária: a partir de 60 anos de idade. A amostra teve a seguinte composição racial: 21 idosos brancos (91\%) e 2 descendentes afro-americanos (9\%). Escolaridade: 17 idosos (74\%) analfabetos e 5 (26\%) alfabetizados; sendo 10 (43\%) solteiros e $12(52 \%)$ sem filhos. Ficou evidenciado que as autoridades ligadas à área de saúde precisam, desde já, estar atentas e desenvolver projetos relativos à prevenção de depressão em idosos, utilizando como grande aliado a família.

Palavras-chave: Idosos; Depressão; Inventário de Depressão de Beck - BDI-II.

\footnotetext{
*Centro Universitário de Araraquara - Uniara.

**Especialista em Enfermagem do Trabalho - UFSCar; Mestre e Doutora em Enfermagem na linha de Pesquisa Educação em Saúde e Formação de Recursos Humanos pelo Departamento de Enfermagem Psiquiátrica e Ciências Humanas da USP.
} 


\section{A PARTICIPAÇÃO SOCIAL NA IMPLEMENTAÇÃO DO PROJETO BANCOS COMUNITÁRIOS NAAMAZÔNIA: UMAANÁLISE DE REDES SOCIAIS}

MAIA, Mara*

\section{RESUMO}

A região Norte do Brasil é um espaço marcado por contradições do desenvolvimento. Esse quadro de desequilíbrio entre crescimento econômico e desenvolvimento social gerou distorções nos níveis de desigualdades, o que mobilizou setores da sociedade na busca de alternativas para combatê-las. Dada a dimensão estrutural e multidimensional da pobreza no Brasil, tais esforços têm possibilitado melhoras expressivas nos indicadores sociais; porém, ainda predominam ações fragmentadas, compensatórias e insuficientes. Diante desse contexto, o presente trabalho se propõe a analisar a participação social na construção de redes a partir de estudo empírico realizado no Banco Comunitário Liberdade, em Manaus. Para tanto, será empregada a metodologia de análise de redes a partir do desenho de suas estruturas sociais, que possibilita confrontar o montante de capital social disponível. O projeto Bancos Comunitários na Amazônia tem por objetivo promover a inclusão financeira e a autogestão dos recursos econômicos na região, com a finalidade de geração de emprego e renda baseada em empreendimentos populares autogestionários, com foco no desenvolvimento local sustentável. Assim sendo, a pesquisa busca identificar os atores atuantes e a funcionalidade da rede social e a sua capacidade de mobilizar recursos junto aos diversos campos institucionais ou organizacionais (sociedade civil, igreja, govemo, cooperativas, associações, etc.) para o seu funcionamento. A articulação das organizações como instrumentos de desenvolvimento traz uma nova concepção para as políticas sociais, que são a construção das redes sociais. Essa nova forma de diálogo se mostra eficaz nas políticas sociais autogestionáras com foco na sustentabilidade; porém, sua lógica de gestão é um componente desafiador para os novos contextos. Um conjunto de forças colaborou para a implementação do projeto. O Instituto Capital Social da Amazônia e a Secretaria de Trabalho e Desenvolvimento Social, órgão representativo da Prefeitura Municipal de Manaus, foram os principais responsáveis pela mobilização local do projeto, estando presentes outros segmentos. Dada a dimensão estrutural e multidimensional da pobreza no Brasil, tais esforços têm possibilitado melhoras expressivas nos indicadores sociais, porém ainda predominam ações fragmentadas, compensatórias e insuficientes. Os dados analisados provêm da pesquisa empírica no Banco Liberdade, onde foram entrevistados vários setores sociais quecompõem o projeto, entre eles as organizações sociais, instituições, microempreendedores, comerciantes, e sociedade civil, num conjunto de 17 atores ouvidos. Nesta pesquisa buscaremos destacar a importância da criação de parcerias e outras variáveis na construção da rede social. Destacando também como ações econômicas são determinadas e determinantes por um conjunto abrangente de ações sociais.

Palavras-Chave: Redes sociais; Microfinanças; Desenvolvimento; Manaus; Bancos Comunitários.

*Centro Universitário de Araraquara - Uniara, Araraquara/SP. 


\title{
DANO MORAL COLETIVO AMBIENTAL NO ÂMBITO DO DIREITO DOS RECURSOS NATURAIS
}

\author{
LEMES, Marci Aparecida*; BORINO; Salete*; HERRMANN, Hildebrando*
}

\section{Resumo}

A dignidade humana, que é considerada a essência de todos os direitos personalíssimos (MELO, 2004), e a manutenção da capacidade do ecossistema, além de receberem a proteção constitucional, receberam também a proteção dos direitos difusos. Alegislação pátria prescreve que os bens ambientais pertencem à coletividade e não ao Estado, e que a ofensa a esses bens deve ser reparada e, dentre outras, está elencada a reparação por meio da indenização pelos danos morais coletivos ambientais. Apesar de os legisladores se preocuparem em elaborar leis para a preservação do meio ambiente, incontroverso é que os bens ambientais já foram atingidos e, neste momento, não são mais passíveis de preservação, mas sim de reparação, por meio da reconstituição, ou, quando essa não for mais possível, através da indenização pelos danos patrimoniais e extrapatrimoniais. $\mathrm{O}$ objetivo do artigo é chamar a atenção dos exercitores do direito, em especial, para a importância do direito coletivo ambiental no âmbito do direito dos recursos naturais, fazendo uma breve análise do que seja dano ambiental, sua definição e repercussão na área do dano moral coletivo ambiental, atentando também ao fato de que toda atividade humana, de uma forma ou de outra, afeta o meio ambiente, mais especialmente a atividade de extração de recursos naturais. Pretende-se também demonstrar o dever de reparação pelos danos morais coletivos ambientais.

Palavras-chave: Meio ambiente; Direito dos recursos naturais; Exploração da natureza; Dano moral coletivo ambiental.

*Centro Universitário de Araraquara - Uniara, Araraquara/SP. 


\title{
CONTRADIÇÕES ENTRE O MONOTEÍSMO JUDAICO-CRISTÃO EA NATUREZA: QUESTÕES ESSENCIAIS PARA SE PENSAR UM NOVO ESTAR DO SER HUMANO NO PLANETA
}

\author{
CHADDAD, Flávio Roberto*
}

\section{RESUMO}

Não há dúvidas de que o mundo está passando por um momento crítico e sem precedente em toda a sua história. Entre os meios para sanar essa situação se situa a educação; em seu espectro maior, a Educação Ambiental, que, política por natureza, propõe mudanças na forma do homem se relacionar coma natureza. Isso implica vislumbrar quais os fatores que contribuem diretamente para essa crise. Pesquisas indicam haver três fatores essenciais que fazem com que o ser humano enxergue a natureza e os próprios seres humanos como objetos, meros instrumentos de utilidade, para que os outros seres humanos, geralmente os que têm poder econômico, possam auferir, cada vez mais e mais, lucros: o monoteísmo judaico-cristão; a razão, que faz com que o homem, "ser pensante", seja superior à natureza; e o capital. O objetivo deste trabalho foi analisar o monoteísmo judaico-cristão. Como metodologia do trabalho foi realizada uma revisão bibliográfica e como metodologia de análise se utilizou o materialismo histórico dialético, como forma de analisar os problemas vigentes. O método permite que o homem parta do real aparente e, através de abstrações, consiga chegar ao concreto pensado. Os resultados até aqui conseguidos mostram que há uma grande influência do monoteísmo judaico-cristão como meio de ação do homem sobre a natureza. Ele faz com que o homem, "imageme semelhança de Deus e possuidor de alma", se enxergue como um ser superior a ela. Não há uma identidade entre o homem e a natureza, que na visão dos cristãos é a desalmada. Isso abre espaço para que o homem, imagem e semelhança de Deus na Terra, se utilize da natureza, "a desalmada", da maneira que bem entender, pois ela apenas serve para manter sua parte imperfeita funcionando durante esta vida efêmera na Terra.

Palavras-chave: Crise ambiental; Educação Ambiental; Gestão Ambiental; Monoteísmo judaico-cristão.

*Centro Universitário de Araraquara - Uniara, Araraquara/SP. 


\section{NORMAS DE PUBLICAÇÃO}

A Revista Uniara é uma publicação multidisciplinar do Centro Universitário de Araraquara - Uniara que tem por finalidade divulgar artigos originais de diferentes áreas do conhecimento.

Os textos submetidos não deverão ser apresentados em outro periódico e, após a sua aceitação, será solicitada dos autores a transferência dos direitos autorais. Os manuscritos serão encaminhados a pareceristas, que deverão analisar o valor científico do trabalho.

Os trabalhos deverão ser enquadrados em uma das seguintes modalidades:

a) Artigos originais: trabalhos inéditos de pesquisa com no máximo 25 páginas, incluindo figuras, tabelas, quadros, esquemas, etc.;

b) Artigos de revisão: sínteses de conhecimentos disponíveis sobre determinado tema, mediante análise e interpretação de bibliografia pertinente, com no máximo 25 páginas;

c) Comunicações breves: resultados preliminares de pesquisa, com no máximo 10 páginas incluindo figuras, tabelas e referências;

d) Resenhas ou análise crítica de livros: máximo 4 páginas;

e) Seção temática (a convite): seção destinada à publicação de trabalhos sobre temas de interesse atual.

\section{PREPARAÇÃO DOS MANUSCRITOS}

As submissões dos manuscritos deverão atender aos seguintes critérios:

a) Os textos deverão ser digitados em espaço duplo, fonte Times New Roman, tamanho 12;

b) Título do artigo, nome e endereço dos autores (nome completo por extenso e filiação acadêmica). Havendo autores com diferentes endereços, eles deverão vir imediatamente após o nome de cada autor. Agrupar os autores por endereço. O autor para correspondência e seu endereço, incluindo e-mail, deverão ser assinalados com asterisco;

c) Os resumos deverão ser redigidos em português e em inglês, em um único parágrafo (máximo de 250 palavras), de modo claro e conciso contendo: objetivo, procedimentos metodológicos, resultados e conclusões, acompanhados de 3 palavras-chave, também redigidas em português e em inglês;

d) Figuras (incluindo gráficos, esquemas, etc.) deverão utilizar o mesmo padrão de letra do texto, ser numeradas sequencialmente, em algarismos arábicos, com a respectiva legenda. As figuras deverão ser encaminhadas em folhas separadas, com a localização aproximada indicada no texto. Ilustrações (fotografias, gráficos, desenhos, mapas, etc.) deverão ser enviadas e em preto-e-branco, em arquivos formato jpg e/ou tif.

e) Só deverão ser utilizadas unidades de medida, símbolos e abreviaturas padronizados. Abreviações não familiares deverão ser definidas na primeira vez em que forem apresentadas no texto;

f) Os artigos referentes a pesquisas envolvendo seres humanos e animais deverão ser acompanhados de uma cópia do parecer emitido por um Comitê de Ética em Pesquisa aprovando o desenvolvimento da pesquisa;

g) Os manuscritos deverão conter, de modo geral: introdução, metodologia, resultados e discussão, conclusão, agradecimentos e referências. Recomendase evitar a subdivisão do texto em um grande número de subtítulos ou itens.

h) As referências deverão ser elaboradas de acordo com as normas da Associação Brasileira de Normas Técnicas (ABNT), conforme formatos descritos a seguir:

\section{1) LIVRo}

SOBRENOME, Nome. Título em destaque: subtítulo. Edição. Cidade: Editora, ano. Número de volumes ou páginas. (Série).

Edição do livro:

- se for em português colocar: 2 . ed.

- se for em inglês colocar: 2nd ed.

\section{2) Capítulo de livro}

Autor do capítulo diferente do responsável pelo livro todo:

AUTOR DO CAPÍTULO. Título do capítulo. In: AUTOR DO LIVRO. Título do livro em destaque. Edição. Cidade: Editora, ano. volume, capítulo, 
página inicial-final da parte.

Único autor para o livro todo

AUTOR DO CAPÍTULO. Título do capítulo. In: . Título do livro em destaque. Edição. Cidade: Editora, ano. volume, capítulo, página inicial-final da parte.

\section{3) Artigo de periódico}

SOBRENOME, Nome. Título do artigo. Título do periódico em destaque, v., n., p. inicial-final, mês abreviado no idioma de origem. ano de publicação.

\section{4) Artigo de jornal}

AUTOR do artigo. Título do artigo. Título do jornal em destaque, cidade de publicação, dia, mês abreviado. Ano. Número ou Título do Caderno, Seção ou Suplemento, p. seguido dos números da página inicial e final, separados entre si por hífen.

\section{5) DissertaÇão, tese e monografia}

SOBRENOME, Nome do autor. Título em destaque: subtítulo. Ano de publicação. Número de volumes ou folhas. Categoria (Curso) - Instituição, Cidade da defesa, ano da defesa.

6) EvENTo CIENTÍFICO - CONSIDERADO NO TODO TÍTULO DO EVENTO, número., ano, cidade de realização. Título da publicação em destaque. Cidade de publicação: Editora, data. Páginas ou volumes.
7) EvENTO CIENTÍFICO - CONSIDERADO EM PARTE (Trabalhos apresentados e publicados)

AUTOR DO TRABALHO. Título do trabalho: subtítulo. In: NOME DO EVENTO,em número, ano, cidade de realização. Título da publicação em destaque. Cidade de publicação. Título do documento (Anais, proceedings, etc. em destaque), local: Editora, ano. Página inicial-final do trabalho.

\section{8) NORMA TÉCNICA}

NOME DA ENTIDADE RESPONSÁVEL. Título da norma em destaque: subtítulo. Cidade de publicação, ano. Número de páginas.

\section{9) Documento eletrônico}

Após a indicação dos dados de cada documento, acrescentar as informações sobre a descrição física do meio eletrônico respectivo.

- SE FOR CD-ROM acrescentar o: Número de CD-ROM

- SE FOR ON-LINE acrescentar: Disponível em: <endereço eletrônico>. Acesso em: dia mês abreviado. Ano.

Os manuscritos que não estiverem de acordo com as Normas de Publicação serão devolvidos aos autores.

Os textos para publicação deverão ser enviados por meio eletrônico para revistauniara@uniara.com.br. Informações pelo telefone: (16) 3301-7126. 